\title{
Hoshin Kanri X-Matrix Drives Engineering Leadership Program Success
}

\section{Dr. Bruce DeRuntz, Southern Illinois University Carbondale}

Bruce DeRuntz, PhD, is a Professor in the College of Engineering at Southern Illinois University Carbondale where he teaches classes on project management and leadership. He consults with universities and companies on their leadership development of human resources for six sigma and project management teams. He is the Director of SIUC's Leadership Development Program and the former Editor of the ASQ's Quality Management Forum. He is a Fellow with the American Society for Quality and holds certifications for Six Sigma Black Belt and Quality Engineer.

\section{Dr. Rhonda K Kowalchuk, Southern Illinois University Carbondale Dr. John W. Nicklow, Southern Illinois University, Carbondale}

John W. Nicklow received B.S. and M.S. degrees in Civil Engineering from Bucknell University (PA) in 1993. In 1998, he earned a Ph.D. in Civil Engineering from Arizona State University (AZ). In the same year, he joined the College of Engineering at Southern Illinois University Carbondale (SIU) as an Professor in the Department of Civil and Environmental Engineering, Dr. Nicklow was recognized by the SIU College of Engineering and the American Society of Civil Engineers for teaching excellence. He has attracted funding for both education-related initiatives and for research activities in water resources systems management. He has served in a variety of positions, including Acting Chair, Assosiate Dean, and Assistant Provost. Dr. Nicklow was appointed Provost and Vice Chancellor at SIU. Dr. Nicklow is a registered professional engineer in Arizona and Illinois, a certified professional hydrologist (American Institute of Hydrology), a Fellow of the American Society of Civil Engineers, and a diplomate of water resources engineering (American Academy of Water Resources Engineers). 


\title{
Hoshin Kanri X-Matrix Drives Engineering Leadership Program Success
}

\begin{abstract}
Universities with technical leadership development programs are challenged with demonstrating the effectiveness of these training programs with measurable results. This is an especially daunting task given the fact that we are trying to inspire undergraduate students who already feel over-burdened by a rigorous major and little to no work experience to know the value that leadership skills can bring to their career. The solution is to apply the Hoshin Kanri X-matrix to the leadership development program so the students can understand how their individual leadership efforts in their own student organizations benefit the entire leadership training program and teach them how to use this valuable engineering tool as a future technical leader.
\end{abstract}

Participants in Southern Illinois University Carbondale's (SIUC's) Leadership Development Program (LDP) are community college transfer students that are seeking a Bachelors of Science degree in an engineering or technology discipline. They have expressed an interest in developing technical leadership skills and were selected for the scholarship and training program through a competitive process that examined their leadership achievements prior to being selected. There have been a total of 32 students participate in the program since fall 2010, with 12 in the current group. There has been a total of 42 participants since the start of the program in 2007 (i.e., the program was conceived in 2006, and the first cohort began in 2007). The students represent a cross-section of two technology and five engineering majors. Participants choose a student organization in the College of Engineering (e.g., Society of Women in Engineering) in which they would like to lead. A student then has their peers assess their leadership effectiveness through the results of the organization's projects. This information is then recorded in the LDP's $\mathrm{X}$-matrix.

The LDP has used the X-matrix over the past three years and the results illustrate a progressive improvement in the overall efficacy of the program each year. The quantitative results demonstrate that students are improving their engineering leadership skills as the program continues to mature. The implications of integrating the X-matrix into a technical leadership development program are many; (1) it becomes a motivational tool that helps participants relate their efforts to become a leader and its impact on their chosen student organization, (2) it develops their understanding of their responsibility to the larger organization, (3) it develops their leadership communication abilities and (4) it develops their skill in using a valuable organizational management tool that can be applied throughout their professional career. Training future technical leaders to apply engineering management tools while in college should lead to greater success for student development, their projects, their college, the leadership program, their employers, and their countries.

\section{Introduction}

Developing the next generation of engineering leaders is an economic imperative that is shared by most countries. The National Academy of Engineering ${ }^{1}$ (NAE), Engineer of 2020 initiative emphasizes the need for future engineers to work in a technologically advanced global economy that is constantly changing. A goal of the initiative is "to educate technically proficient engineers who are broadly educated, see themselves as global citizens, can be leaders in business and public service, and who are ethically grounded." (p. 51). Universities have responded to this 
imperative by creating technical leadership development programs ${ }^{2}$. SIUC'S College of Engineering also responded by creating its Leadership Development Program (LDP) in 2006 with the support from Advanced Technology Services (ATS) and later, the National Science Foundation.

While creating a technical leadership development program is an important first step, the efficacy of such a program is the most important outcome and wherein lies the greatest challenge. SIUC'S College of Engineering has adapted an engineering management tool, Hoshin Kanri X-matrix, to effectively manage the large scale program, to teach students how to use this important tool, and to quantitatively demonstrate the efficacy and impact of the program, while meeting the motivational needs of the college's student leaders to perform at their best (see Figure 1).

Figure 1

Process of integrating the X-Matrix into the LDP

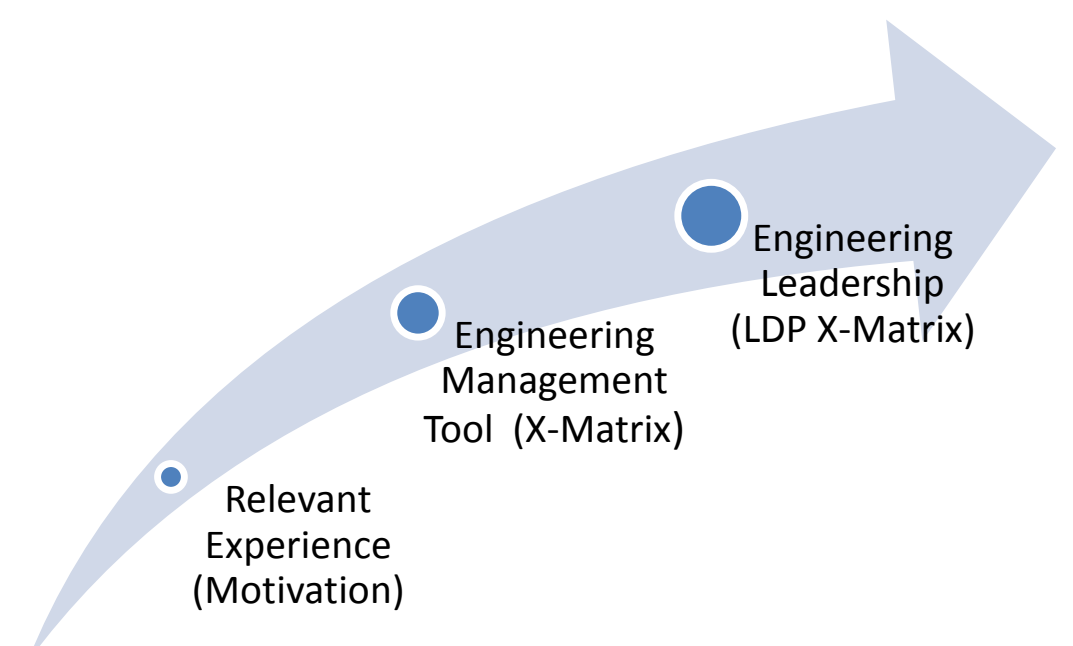

\section{The Leadership Development Program}

The LDP is a rigorous two year training program that teaches students character, interpersonal, team-building, and leadership skills. While there is some classroom based education in the program, the program director believes that leadership is best learned when students apply it to leading their project teams, such as ASCE Steel Bridge, Concrete Canoe, and SAE Baja competitions. Many of the students serve as leaders and presidents of the College's Registered Student Organizations (RSO) project teams.

The program uses a selection process and is open to community college transfer students with Junior standing. First year students (Juniors) learn to lead themselves and projects of short duration. Examples of learning to lead themselves include arriving early and prepared for every meeting, learning to hold themselves accountable, and adopting the cultural values of the LDP. Examples of leading short-term projects include achieving excellence in organizing a campus blood drive, river clean up, trail maintenance, community clean up, Habitat for Humanity build, and a food bank work day. Team members experience a lot of personal growth their first year in 
the program. Second year students (Seniors) have the responsibility of leading an RSO project team for the year and mentoring the first year students. These students attest to the difficulties in motivating peers on the project teams, but in the end they also experience a lot of personal growth and an increase in their self-confidence.

\section{Relevant Experience}

It was recognized in the early stages of the LDP that the students struggled to be motivated to strive for excellence without a common goal and vision that they all shared. The importance of finding the means to connect with the students so they can understand the value of learning fundamental leadership skills early in their career cannot be overstated. Most traditional collegeage students are just beginning to learn how to take care of themselves and resist the idea of sacrificing their time and putting forth extra effort for leadership training.

Part of the reason that makes it difficult for a student to comprehend the value of this skill set is because it can be a somewhat nebulous concept to them - even sometimes having preconceived beliefs that leaders are born. Consider the fact that up until this point in their life, they have mostly received praise, reinforcement, and recognition for academic and sports achievements. Both of these activities have an inherent different motivating factor to learning leadership because (1) they provide periodic quantitative feedback, (2) academics are an individual activity and (3) sporting events provide personal coaching on a weekly basis. If the LDP was going to be able to demonstrate its efficacy, there must be a means employed for making the learning relevant and the training experiential.

Engineering education is greatly enhanced when students get to apply their technical knowledge to complex real-life projects. Their learning is further enhanced when they learn the value of how to properly manage and lead a project. The combination of having students lead their RSO student competition teams and using the Hoshin Kanri X-matrix was the solution for motivating and managing our students to strive for excellence. The X-matrix was introduced to the LDP as a means of uniting the students from different RSOs to work towards a common goal, to teach them the value of this powerful tool, and to drive success in the LDP and their student project teams.

This paper addresses the fundamental process for constructing and using an X-matrix, and then describes how it is applied to achieve success in SIUC'S LDP.

\section{Engineering Management Tool}

Most major organizations have developed mission and vision statements to serve as a goal and constant reminder of what the organization stands for and what it's working towards. To achieve their mission and vision, organizations engage in developing a strategic plan every one to five years. In the strategic planning process, the CEO or organizational leaders assess the challenges of the current business environment and formulate strategic objectives. These objectives are then passed down throughout the organization for the divisions to develop tactical means of achieving their portion of the strategic objectives.

Linking strategic goals to tactical execution has been a challenge for many organizations as they struggle to fulfill their strategic plan. The Hoshin Kanri X-matrix serves to provide a methodical, 
logical, visual, and quantitative means for organizing and assessing these massive strategic initiatives and is often used as the project plan for large organizations to achieve their mission and vision statements. The X-matrix is based upon the Hoshin Kanri strategic planning process developed by Dr. Yoji $\mathrm{Akao}^{3}$. Hoshin Kanri is a Japanese term which can translate to, "Ship in a storm going in the right direction". The power of an X-matrix is its ability to breakdown a goal into increasingly smaller tasks and linking them to a resource, much the same way a project plan uses a work breakdown structure. The X-matrix is typically constructed using a software program such as Microsoft Excel to assist in the data computations.

The basic steps to constructing an X-matrix include: (see Figure 2)

1. Determine key strategic objectives using a "SMART" format

2. Formulate main initiatives on how to achieve the key objectives

3. Develop tactical actions to execute the main initiatives

4. Identify the key metrics used to assess tactical actions

5. Determine the resource who will have responsibility for the tactical actions

Figure 2

X-Matrix Format

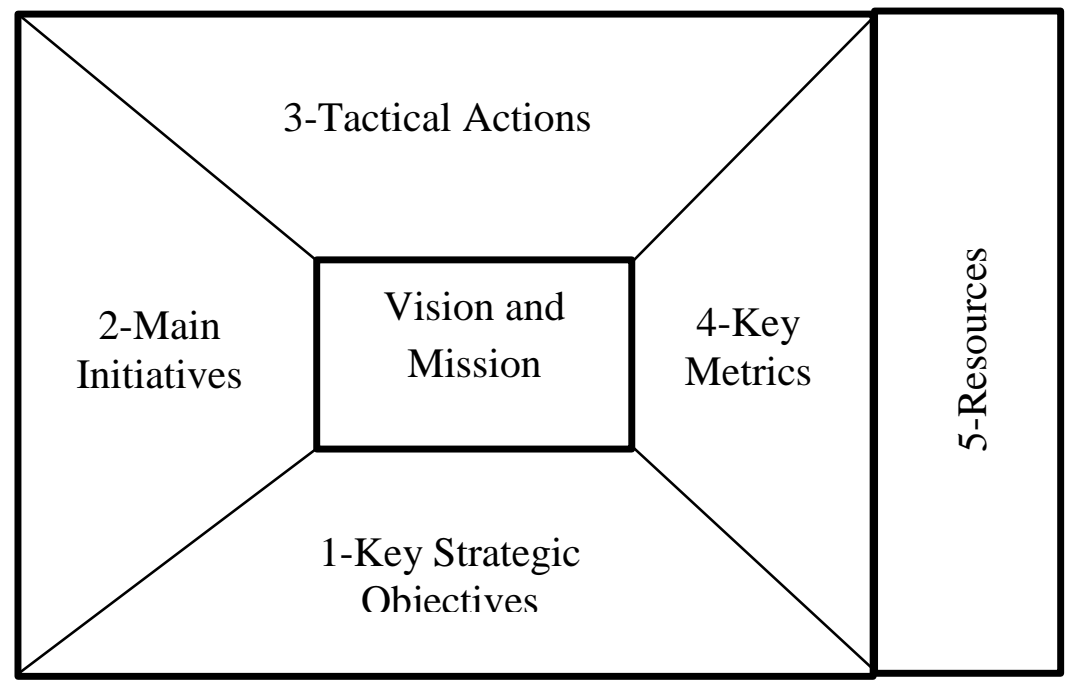

When establishing Key Strategic Objectives it is important that they conform to the SMART goal format. Without being written to these specifications it would be nearly impossible to have success in the successive steps due to the vagrancies of a poorly written objective. The following represent the SMART specifications:

- Specific - target a specific area for improvement.

- Measurable - quantify or at least suggest an indicator of progress.

- Assignable - specify who will do it.

- Realistic - state what results can realistically be achieved, given available resources.

- Time-related-specify when the result(s) can be achieved. 
Figure 3

Portion of the LDP's X-Matrix

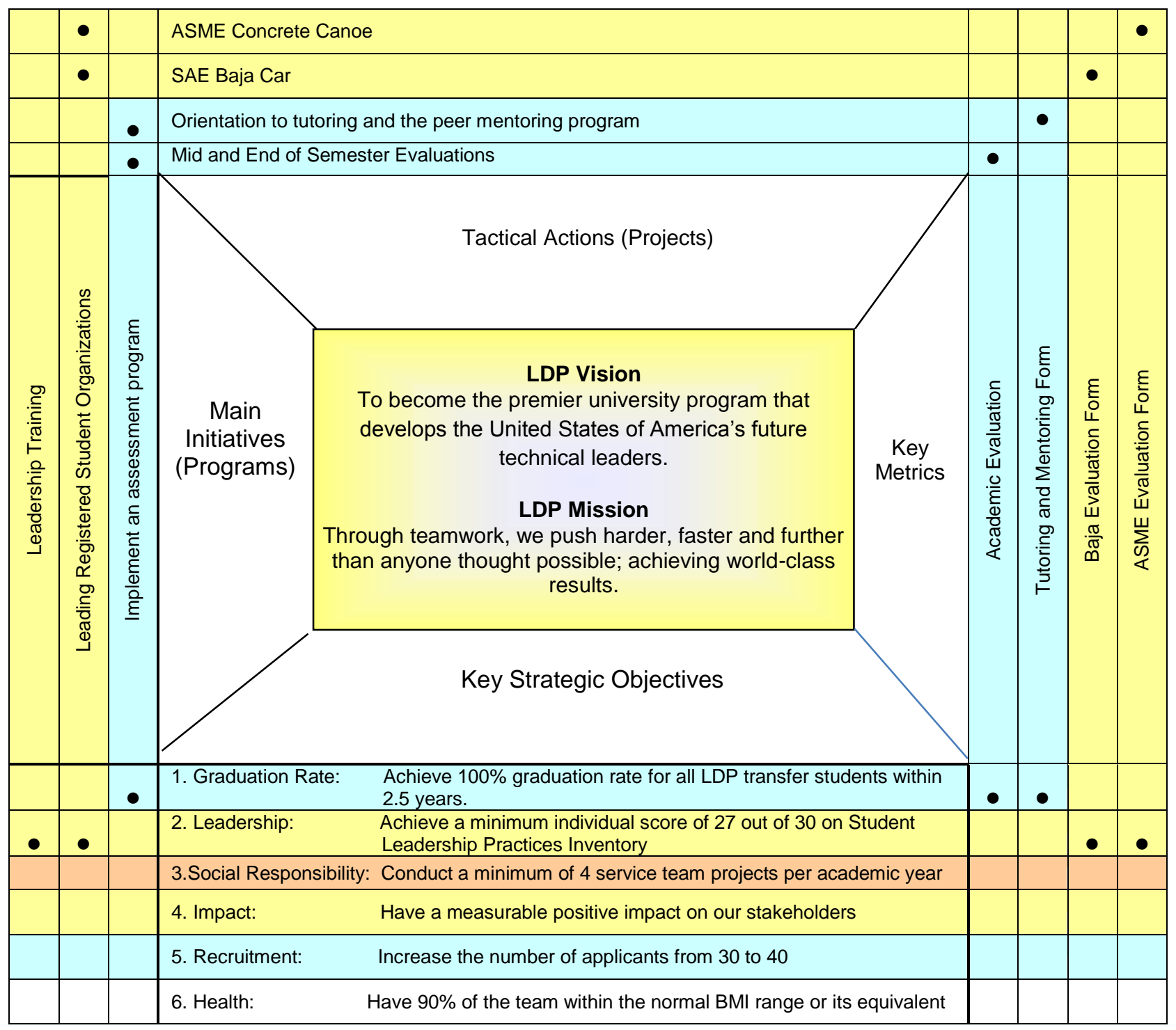

\section{Engineering Leadership}

The authors will now present how the X-matrix is applied to the LDP to teach engineering leadership and demonstrate the efficacy of the program. Each step in the process will be explained and illustrated through the actual content of the current LDP. Due to the size of the LDP X-matrix graph, not all of the Main Initiatives, Tactical Actions, Key Metrics and Resources can be shown (see Figure 3 and Appendix).

The process begins with reviewing and renewing our student's commitment to the program's vision and mission. This is a very important step because this is the time to communicate what all of the stakeholders stand for and are working towards. A lot of time is spent on this initial step to ensure everyone's complete understanding of our vision and mission and to affirm buy-in 
for each of the student participants. The LDP's vision and mission statements have been developed over the past seven years.

Vision Statement: To become the premier university program that develops the United States of America's future technical leaders.

Mission Statement: Through teamwork, we push harder, faster and further than anyone thought possible, achieving world-class results

\section{Key Strategic Objectives}

The team is then asked what kind of Key Strategic Objectives would reflect our proficiency in achieving our vision and mission. The students have the opportunity to amend the current Key Objectives, but have determined that they are still relevant and timely since being initially established (see Table 1).

Table 1

Key Strategic Objectives with SMART Description

\begin{tabular}{|l|l|}
\hline Key Objective & SMART Description \\
\hline Graduation Rate & $\begin{array}{l}\text { Achieve 100\% graduation rate of all LDP transfer students within } 2.5 \\
\text { years. }\end{array}$ \\
\hline Leadership & $\begin{array}{l}\text { Achieve a minimum individual score of 27 out of 30 on Student } \\
\text { Leadership Practices Inventory }\end{array}$ \\
\hline Social Responsibility & Conduct a minimum of 4 service team projects per academic year \\
\hline Impact & $\begin{array}{l}\text { Have a measurable positive impact on our stakeholders; SIUC, } \\
\text { Carbondale community, ATS, and the Student body }\end{array}$ \\
\hline Recruitment & Increase the number of applicants from 30 to 40 \\
\hline Health & Have 90\% of the team within the normal BMI range or its equivalent \\
\hline
\end{tabular}

\section{Main Initiatives}

Main Initiatives are sometimes called Programs or Top Level Improvement Priorities. This section will often contain multiple initiatives or programs to accomplish the larger Key Strategic Objective. In the LDP, this is where we identify the main type of programs that are needed to achieve a Key Strategic Objective.

Due to space limitations, the authors are only focusing on the Key Strategic Objective of Leadership and following it through the entire X-matrix process. The Main Initiatives for Leadership are as follows:

- Leading Registered Student Organizations (RSO)

- Indirect Leadership Training

- Leading Projects

- Leadership Training

- Team Training 


\section{Tactical Actions}

Just like the Main Initiatives, there are often multiple Tactical Actions required to fulfil a single Main Initiative. Where Main Initiatives are akin to programs, Tactical Actions are akin to projects. This section tends to be the largest section for the LDP, because this is where the specific projects are listed. The following is a partial list of the Tactical Actions that are linked to the Main Initiative of Leading RSOs.

- SAE Baja Car

- ASME Concrete Canoe

- ASME Steel Bridge

- ATMAE Robot

- Leadership Development Program

- Engineering Student Council

\section{Key Metrics}

Key Metrics are the section that quantitatively evaluates each of the Tactical Actions (e.g. projects). The data that is collected for the Key Metrics is always an assessment of the project's success. In the LDP, we associate the project success/failure with the performance of the person/resource that is responsible for leading the project. In the LDP, team members that participate in the projects will collectively rank the performance of each project leader using an evaluation questionnaire. This is a critical element because input is collected from each of the project team members, on each of the questionnaire items and an average is computed. Using the input from a large group of students reduces the subjectivity of the assessment and ensures the integrity of the data.

Assessment questionnaires can generally use a set of standard questions, but can be customized if the project parameters require it. The following standard rating scale is used for all the assessments in order to maintain consistent metrics.

Questionnaire Rating Scale:

10. - Perfect

9. - Almost perfect

8. - Few improvements needed

7. - Some improvements needed

6. - Above average

5. - Average

4. - Below average

3. - Many improvements needed

2. - Very many improvements needed

1. - Failed but completed

0. - Failed and did not complete

Table 2 is an example of a questionnaire that contains the Key Metrics associated with the SAE Baja Car Project. A more comprehensive and accurate evaluation is able to be performed when the key attributes for a project are specified. The highest rating in Table 2 was for the area of Timely. The perfect score of 10 indicates that all of the project team members felt the car was 
completed within the specified time frame. The team registered the lowest rating, with a score of 6 , for the area of Engagement. This "above average" score indicates that the team felt the project leader was not able to achieve full engagement from all of the team's members but did engage most of them. All of the group's Area ratings are averaged to produce an overall mean for the project (e.g., Key Metric).

Table 2

Example of the Evaluation Questionnaire for SAE Baja Car Project

\begin{tabular}{|l|l|c|}
\hline Area & Definition & Group's Assessment \\
\hline Timely & $\begin{array}{l}\text { Was the SAE Baja car completed within the } \\
\text { specified time frame? }\end{array}$ & 10 \\
\hline Safety & Was the project completed in a safe manner? & 8 \\
\hline Engagement & Was everyone actively engaged? & 6 \\
\hline Value & Were the lessons worthwhile? & 7 \\
\hline Preparation & How was the preparation for the project? & 9 \\
\hline Leadership & How well was the project led? Mean & $\mathbf{8 . 2}$ \\
\hline & & M \\
\hline
\end{tabular}

\section{Results}

Once all of the data has been collected, the final step is to calculate the cumulative results (see Table 3). The evaluation data from each of the Key Metrics are averaged together according to the Key Strategic Objective it is linked to (see Appendix). This computed average for each of the Key Strategic Objectives is then averaged to produce an overall mean for achieving the mission and vision of the LDP.

It should be noted again, the data is the cumulative evaluation of a project team leader by the team members. This step is of the utmost importance to ensure the integrity of the assessment data. Additionally, the program director oversees all of the assessments to encourage critical evaluations and guard against inflating assessment ratings.

Table 3 contains the quantitative summary results for the three years that the LDP has been using the X-matrix. The table lists the five Key Objectives, descriptions of each objective and the assessment score for each of the objectives in each of the three years. The mean totals for the past three years are 7.66, 8.02, and 8.90, respectively. These results illustrate a progressive improvement in the overall efficacy of the program. It can be inferred that the students are improving their engineering leadership skills as the program continues to mature. Prior to implementing the X-matrix, the assessment of the program's students was highly subjective. The students are now able to understand the role that they play in achieving the overall vision and mission of the program, receive a thorough assessment of their leadership performance from their peers, and learn a valuable engineering management tool for their future career. 
Table 3

Cumulative Results for the LDP Spanning the Last Three Years (2011-2013)

\begin{tabular}{|l|l|l|l|l|}
\hline Key Objective & SMART Description & 2011 & 2012 & 2013 \\
\hline Graduation Rate & $\begin{array}{l}\text { Achieve 100\% graduation rate of all of our students } \\
\text { within 2.5 years. }\end{array}$ & 9.37 & 9.71 & 9.67 \\
\hline Leadership & $\begin{array}{l}\text { Achieve a minimum individual score of 27 out of 30 } \\
\text { on Student Leadership Practices Inventory }\end{array}$ & 9.12 & 7.67 & 8.92 \\
\hline $\begin{array}{l}\text { Social } \\
\text { Responsibility }\end{array}$ & $\begin{array}{l}\text { Conduct a minimum of 4 service team projects per } \\
\text { academic year }\end{array}$ & 6.14 & 6.99 & 9.36 \\
\hline Impact & $\begin{array}{l}\text { Have a measurable positive impact on our } \\
\text { stakeholders; SIUC, Carbondale community, ATS, and } \\
\text { the student body }\end{array}$ & 7.00 & 4.25 & 8.88 \\
\hline Recruitment & Increase the number of applicants from 30 to 40 & 6.00 & 10.00 & 7.35 \\
\hline Health & $\begin{array}{l}\text { Have 90\% of the team within the normal BMI range or } \\
\text { its equivalent }\end{array}$ & 8.33 & 9.50 & 9.22 \\
\hline & \multicolumn{1}{|c}{ Mean } & $\mathbf{7 . 6 6}$ & $\mathbf{8 . 0 2}$ & $\mathbf{8 . 9 0}$ \\
\hline
\end{tabular}

Additional evidence of the program's effectiveness is offered through qualitative analysis. The Director of the LDP always tries to keep in perspective the 'end-goal' of the program. While it is very important to be able to measure the effectiveness of the student's leadership development while in the program, the end-goal is how this training transcends them into becoming leaders in their technical careers. ATS is a company with approximately 3500 employees world-wide and a leader in its field. They have been the prime sponsor of the LDP and have hired 13 of the program's graduates to date, with the first cohort being hired four years ago. The Vice President of Human Resources offers this assessment of the LDP's effectiveness to train technical leaders;

"SIUC'S Leadership Development Program does an outstanding job of preparing the students to enter the workforce with the readiness to assume leadership positions quickly. ATS utilizes this program as one of our key talent pools for leadership roles. Through the program's rigorous academic and extra-curricular requirements, I have found that these graduates have an exceptional work ethic, take initiative, and strive for excellence much more than the typical college graduate." (James Hefti - ATS Vice President of Human Resources)

The LDP student president is the prime person responsible for maintaining the X-matrix each year. While it may be easy to mandate that a group use the X-matrix, it will be more effective if it is accepted and regarded as a beneficial tool by all of the LDP students. Former LDP President Michael Uphoff says "using the X-matrix in the LDP helped me keep focused on the direction we were heading and stay organized. Surprisingly, other students that I introduced it to outside of engineering found it to be very useful and said that they benefited greatly from it. It is a great tool for anyone looking to organize their goals in a strategic and systematic way." This same sentiment is shared by all of the past and present LDP presidents, because as they explain it, the $\mathrm{X}$-matrix provides them with invaluable feedback of their leadership and is their strongest tool for organizing and leading change. 


\section{Conclusion}

There is great value in providing students with the opportunity to learn and use engineering management tools such as the X-matrix for strategic planning and apply it to applied projects just as they would in their professional career. The benefits of integrating the X-matrix into a technical leadership development program are many; (1) it becomes a motivational tool that helps participants relate their efforts to become a leader and its impact on their chosen student organization, (2) it develops their understanding of their responsibility to the larger organization, (3) it develops their leadership communication abilities and (4) it develops their skill in using a valuable organizational management tool that can be applied throughout their professional career.

Sharing the success of applying this tool to a College of Engineering's student leadership development program will have far-reaching benefits for achieving the next generation of engineering leaders. By training future technical engineering leaders to apply engineering management tools while in college, should lead to greater success for student development, their projects, their college, the leadership program, their employers, and their countries.

The Hoshin Kanari X-matrix for strategic planning is an incredibly powerful tool for organizing and communicating the mission, vision, goals, responsible members, and metrics of a large organizational initiative. It should not be reserved for just technical leadership programs, but can also be applied on a micro scale for student project teams, all the way to the macro scale of the undergraduate student government. Not only do students benefit from learning such a valuable organizational tool, but they genuinely appreciate the enhanced communication and organization this tool brings to their organizations.

\section{Acknowledgement}

This material is based upon work supported by the National Science Foundation under Grant No. DUE 0966274 and ATS. Any opinions, findings, and conclusions or recommendations expressed in this material are those of the authors and do not necessarily reflect the views of the National Science Foundation.

\footnotetext{
Bibliography

${ }^{1}$ National Academy of Engineering (2005). Educating the engineer of 2020: Adapting engineering education to the new century. Washington, DC: The National Academies Press.

${ }^{2}$ Gordon, B. (2012). Toward a new engineering education consensus: Ideas from industry and academia for inculcating and fostering leadership skills. Danvers, MA: The Gordon Foundation. ISBN 9780982548554

${ }^{3}$ Akao, Y. (1991). Hoshin Kanri, policy deployment for successful TQM. New York: Productivity Press. ISBN 1-56327311-X.

${ }^{4}$ Doran, G. T. (1981). There's a S.M.A.R.T. way to write management's goals and objectives. Management Review, 70(11), 35-36.
} 
Appendix

Complete Strategic X-Matrix for the Leadership Development Program

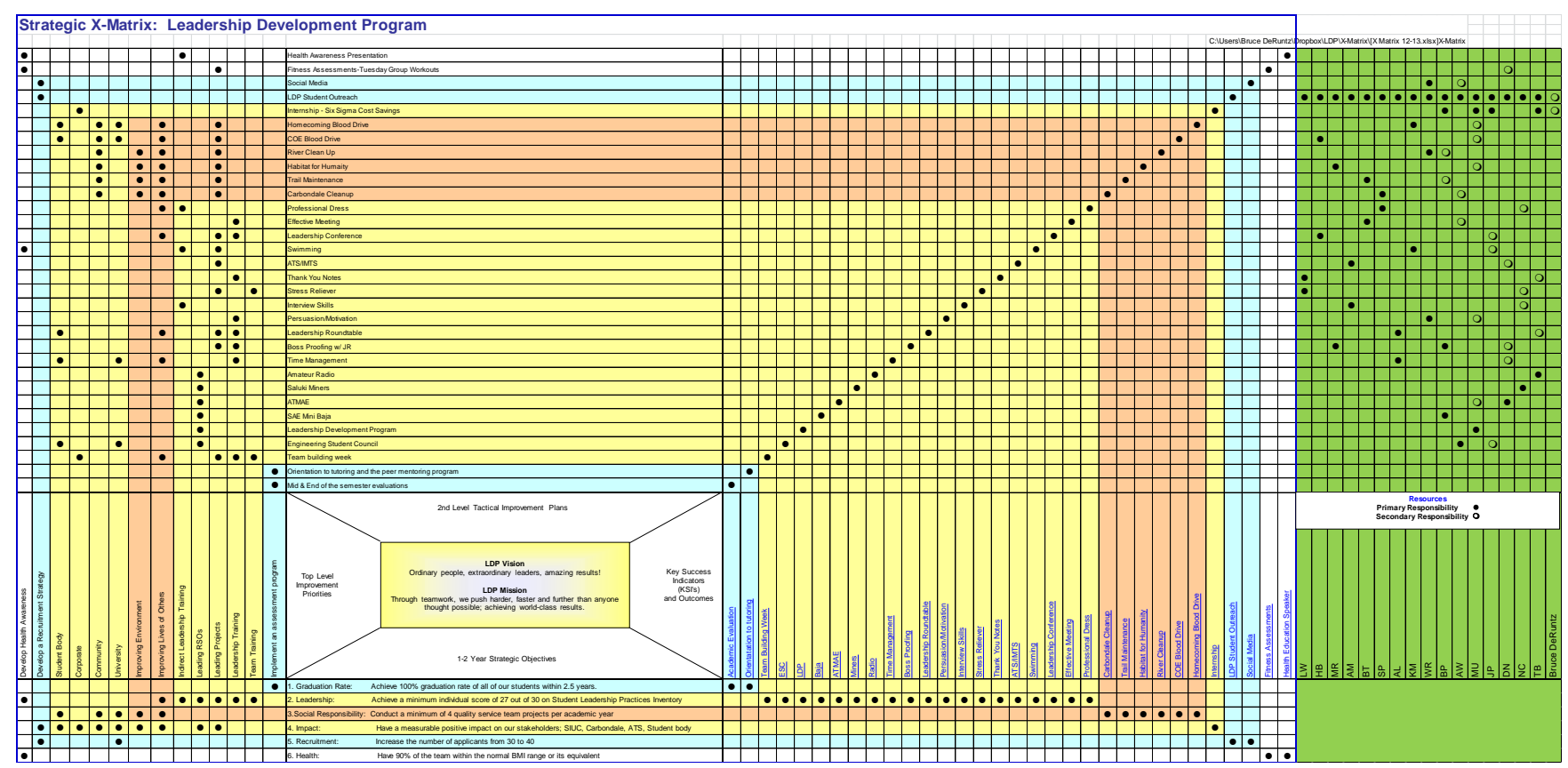

